\title{
An Update on the Global Initiative for Chronic Obstructive Lung Disease 2017 Guidelines With a Focus on Classification and Management of Stable COPD
}

\author{
Robert M Burkes MD and James F Donohue MD
}

\author{
Introduction \\ GOLD ABCD Assessment Tool \\ Therapeutic Approach Based on GOLD Classification \\ GOLD Class B \\ GOLD Class C \\ GOLD Class D \\ Safety of Inhaled Therapies \\ Summary
}

\begin{abstract}
The 2017 Global Initiative for Chronic Obstructive Lung Disease (GOLD) guidelines offer important changes to the assessment and management of stable COPD of importance to practitioners, respiratory therapists, pharmacists, and nurses who care for patients with COPD. Therapies are now chosen based on the burden of symptoms and the history of COPD exacerbations, and inhaler regimens are modifiable based on continual clinical reassessment. Although identifying the degree of airway obstruction remains important for informing the clinical status of the patient with COPD, $F_{E V}$ is no longer used to direct the therapeutic approach. Therapies and modes of inhaled medication delivery for each GOLD grouping have been modified and reflect the need for reevaluation of patient symptoms and COPD exacerbation history as an indicator to add or withdraw therapies. As the knowledge of this important disease continues to expand, exacerbation and symptom prevention in patients with stable COPD will remain as an important target of COPD therapies and research. Novel drug combinations and delivery devices are sure to positively affect the practitioner's approach to patients with stable COPD. The new 2017 GOLD guidelines represent a step toward personalized care of the patient with COPD. Key words: COPD; inhalers; COPD exacerbation; dyspnea. [Respir Care 2018;63(6):749-758. (C) 2018 Daedalus Enterprises]
\end{abstract}

\section{Introduction}

The 2017 Global Initiative for Chronic Obstructive Lung Disease (GOLD) guidelines ${ }^{1}$ have a number of important changes that will influence the care of patients with COPD. The ABCD classification tool has been modified to include only symptoms (by either the modified Medical Research Council [mMRC] dyspnea scale ${ }^{2}$ or the COPD Assessment $\mathrm{Test}^{3}$ ) and exacerbation history. ${ }^{1,4}$ Although imperative for diagnosis and grading of severity, $\mathrm{FEV}_{1}$ is no longer integral to the $\mathrm{ABCD}$ scheme that directs therapy. ${ }^{1}$ The guidelines for prescribing inhaled medications have changed, along with the classification system. Utilization of the therapeutic mainstays of COPD, short-acting bronchodilators (either $\beta$-2 agonists or muscarinic antagonists), long-acting muscarinic antagonists (LAMA), long-acting $\beta$-2 agonists (LABA), combination LABA/LAMA, and the addition of inhaled corticosteroids (ICS), either combined with a LABA, as an additional therapy to LABA/LAMA, or as a monotherapy have been revisited. ${ }^{1}$ Further, the GOLD writing committee highlights new recommendations in the assessment of proper inhaler technique, hospital discharge criteria, and comorbidity assessment and management. ${ }^{1}$ New inhaled agents and novel combinations (in multiple forms, 
including pressurized metered-dose inhalers with and without spacer devices, and dry powder inhalers) are becoming available and will broaden treatment options in the future. Also, the availability of triple fixed-drug combinations that include LABA/LAMA/ICS in a single inhaler is imminent. ${ }^{5,6}$ Herein, the pertinent highlights of the 2017 update of the GOLD guidelines ${ }^{1}$ are reviewed.

\section{GOLD ABCD Assessment Tool}

The GOLD writing committee suggests that assessment of COPD severity by spirometric findings alone is not sufficient because $\mathrm{FEV}_{1}$ is not strongly correlated to symptoms or patient health status ${ }^{7}$ and is most useful as a predictor of clinical outcomes at the population, not the individual, level. ${ }^{1}$ Previous iterations of the GOLD classification system used a combination of air-flow limitation, symptoms, and exacerbation history to determine the $\mathrm{ABCD}$ grade. ${ }^{8}$ Based on the performance of this classification system versus earlier iterations and the possibility for confusion between the multiple possible modifiers of COPD grouping, the writing committee sought to make the spirometric grading of COPD separate from a symptom- and exacerbation rate-focused assessment. ${ }^{1,9,10} \mathrm{Be}$ cause of this, the GOLD guidelines ${ }^{1}$ suggest that COPD be classified with a number to represent the air-flow limitation by $\mathrm{FEV}_{1}$ and a letter to describe the symptom burden and risk of exacerbation for a given patient. Therapeutic approach is based on a combination of the presence of symptoms and exacerbation history, whereas the numerical reporting of GOLD classification is separately used to inform about the clinical status of the patient.

The GOLD writing committee suggests the use of one of two possible tools to assess symptom burden in patients with stable COPD. The mMRC focuses on symptoms of breathlessness or dyspnea, and correlates well to patients' general health status and is superior to spirometric airway obstruction in the prediction of 5-y mortality. ${ }^{2,11}$ The

Drs Burkes and Donohue are affiliated with Division of Pulmonary Diseases and Critical Care Medicine, University of North Carolina at Chapel Hill, Chapel Hill, North Carolina.

Dr Donohue discloses relationships with AstraZeneca, Boeringer-Ingelheim, GlaxoSmithKlein, Novartis, Mylan, Sunovion, Teva, Gilead, InsMed, Aradigm, PneumRx, and CSA. Dr Burkes has disclosed no conflicts of interest.

Dr Donohue presented a version of this paper at the 56th RESPIRATORY CARE Journal Conference, Respiratory Medications for COPD and Adult Asthma: Pharmacologic Actions to Clinical Applications, held June 2223, 2017 in St Petersburg, Florida.

Correspondence: James F Donohue MD, 130 Mason Farm Rd, CB \#7020, Chapel Hill, NC 27599. Email: james_donohue@med.unc.edu.

DOI: $10.4187 /$ respcare.06174
mMRC is also the most expedient way to assess symptoms in the examination room because it focuses on a single question of asking the patient to identify with a functional status description that best describes him or her. A drawback of the mMRC is that it only evaluates dyspnea among the multiple symptomatic manifestations of COPD, and, although the cut point for symptomatic disease of mMRC of $\geq 2$ generally correlates to scoring poorly on more comprehensive measures of COPD symptoms, this is not always the case because patients with lower mMRC scores may manifest symptoms apart from dyspnea. ${ }^{12}$

The COPD Assessment Test score is an 8-domain assessment with which a patient grades his or her symptoms on a $0-5$-point scale based on how frequently he or she experiences a particular symptom of COPD. The COPD Assessment Test score results consistent with symptomatic COPD $(\geq 10)$ correlate very closely to the results of more-extensive symptomatic testing. ${ }^{13}$ The use of this questionnaire is limited by the time that may be required for its completion compared with the mMRC, but this can be rectified by requesting patients complete the test while in the waiting room or in the examination room while waiting for the provider. The mMRC and COPD Assessment Test scores can be used independently at the cut points mentioned above in evaluation of COPD symptoms. Patients with mMRC and COPD Assessment Test scores that reflect symptomatic disease are classified into GOLD groups B or D (differentiated by exacerbation history). ${ }^{1}$

The GOLD ABCD classification also takes into account exacerbations of COPD. ${ }^{1}$ Although the exacerbation rate is somewhat affected by the fixed air-flow limitation, the rate of COPD exacerbation is thought to be dependent on factors other than spirometric results. ${ }^{4,14,15}$ The best predictor of future COPD exacerbation is a history of COPD exacerbation. ${ }^{4}$ Exacerbations can be prevented effectively with appropriate inhaled therapy in most patients, ${ }^{5,16-18}$ and, thus, a recent history of exacerbation is an important factor in determining the therapeutic approach. A patient is considered to be a frequent exacerbator (group $\mathrm{C}$ or group $\mathrm{D}$, which are differentiated by symptoms) if a patient has $\geq 2$ COPD exacerbations that required an escalation in inhaler therapy, steroids, or antibiotics as an out-patient, or the patient has $\geq 1$ COPD exacerbation episode that required an emergency department visit or hospital admission within the year before assessment (Fig. 1).

Severe air-flow limitation $\left(\mathrm{FEV}_{1}<50 \%\right.$ predicted) is associated with an increase in risk of COPD exacerbation, mortality, and overall poor prognosis. ${ }^{19}$ As such, the severity of airway obstruction is necessary in the assessment of the patient with COPD, but, as of the 2017 GOLD COPD guidelines, ${ }^{1}$ is not used in the therapeutic strategy. The therapeutic approaches to the GOLD ${ }^{1}$ groups $\mathrm{B}-\mathrm{D}$ are discussed below. Group A, which includes a patient without symptoms and without a recent history of exacerba- 


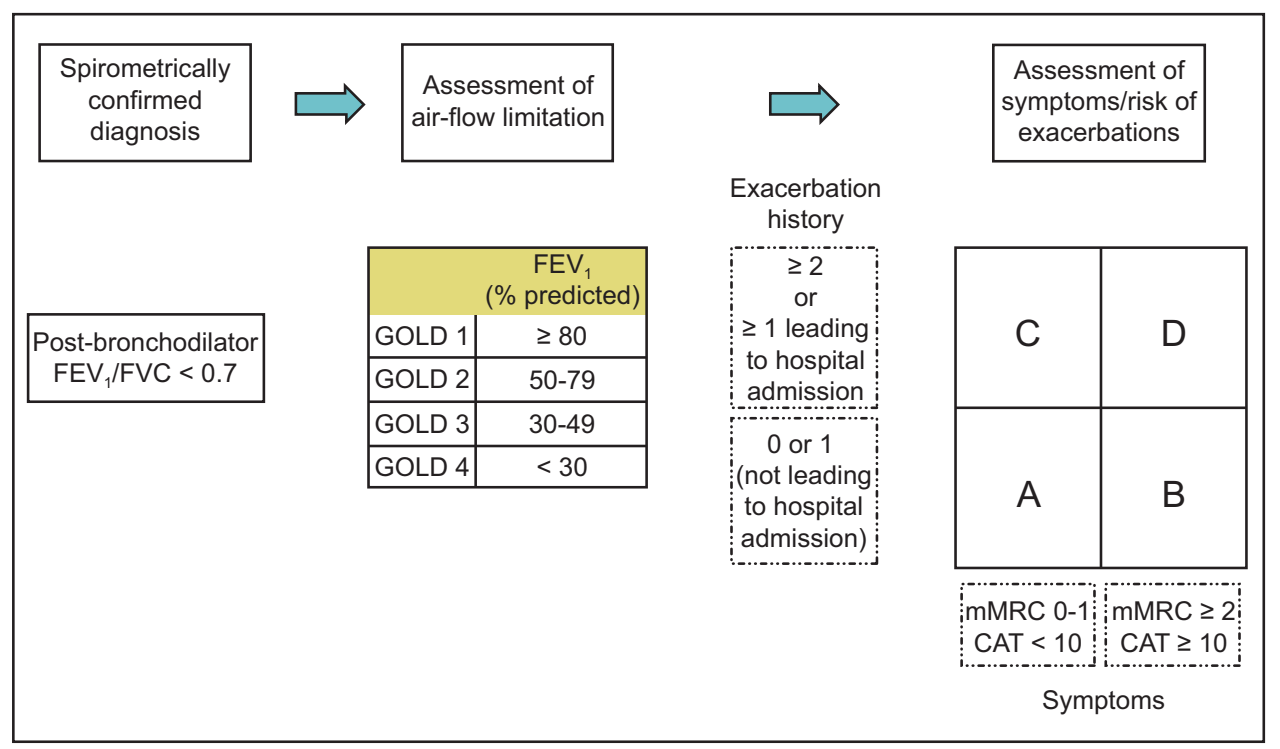

Fig. 1. The Global Initiative for Chronic Obstructive Lung Disease (GOLD) ABCD scheme for classifying patients with COPD with separate appraisal of air-flow limitation and symptoms and/or exacerbation risk. $\mathrm{mMRC}=$ modified Medical Research Council score; CAT $=\mathrm{COPD}$ Assessment Test. From Reference 1, with permission.

tions, and still treated with short-acting bronchodilator monotherapy. In all the groups, patients should receive pneumococcal and influenza vaccinations, smoking cessation counseling and treatment, and be offered referral to pulmonary rehabilitation if symptomatic despite treatment. ${ }^{1}$

\section{Therapeutic Approach Based on GOLD Classification}

\section{GOLD Group B}

In the era of personalized medicine, the patient and his or her interest is a top priority. With the emerging number of inhaled therapies and delivery methods, a patient-centered approach to therapy is paramount. The $\mathrm{B}$ grouping in the GOLD guidelines ${ }^{1}$ is defined by patients who do not frequently have exacerbations but who are symptomatic from COPD. Patients with GOLD B are started on monotherapy of either an LAMA or LABA. For this group of patients, with symptoms present on a daily basis but rare exacerbations, there are no data that have shown superiority of a LAMA or LABA over the other. New GOLD ${ }^{1}$ recommendations call for fixed-dose combined LABA/LAMA if monotherapy does not control dyspnea.

Multiple clinical trials have shown that fixed-dose combinations of LABA/LAMA do not have worse adverse effects and do improve bronchodilation, symptoms, and exacerbation rates when compared with LABA or LAMA monotherapy. ${ }^{20-24} \mathrm{~A}$ meta-analysis also supports the addition of an LABA to a LAMA via the use of a fixed-dose combination was associated with an improvement in health- related quality of life and an increase in pre-bronchodilator $\mathrm{FEV}_{1} \cdot{ }^{25}$ Treatment with fixed-combined LABA/LAMA therapy is also cost-effective. ${ }^{26,27}$ Non-response to bronchodilation can be seen with monotherapy. ${ }^{28}$ The lack of response to monotherapy may be ameliorated by cross-talk between the muscarinic and adrenergic systems in the airways that commonly allows for a synergistic effect between LABAs and LAMAs when combined. ${ }^{29}$

As such, the GOLD guidelines ${ }^{1}$ promote the importance of continual COPD symptom assessment in individual patients and provide direction for practitioners who care for patients who remain symptomatic despite the addition of long-acting bronchodilator monotherapy (Fig. 2). For those patients in GOLD group B who do not improve from the addition of a second, long-acting bronchodilator, the GOLD guidelines ${ }^{1}$ recommend that therapy be rolled back to monotherapy and that other possibilities for breathlessness be identified.

\section{GOLD Group C}

GOLD Group C patients are defined by a history of exacerbations but without breathlessness or other symptoms of COPD on a day-to-day basis. Initial treatment per guidelines is to start a single-agent, long-acting bronchodilator, with a preference for a LAMA based on available studies of exacerbation prevention. ${ }^{30,31}$ If symptoms worsen or exacerbations persist, then the next step in therapy is the addition of a second long-acting bronchodilator, usually through a fixed-dose combination LAMA/LABA, as the addition of an ICS has been associated with an increase in 

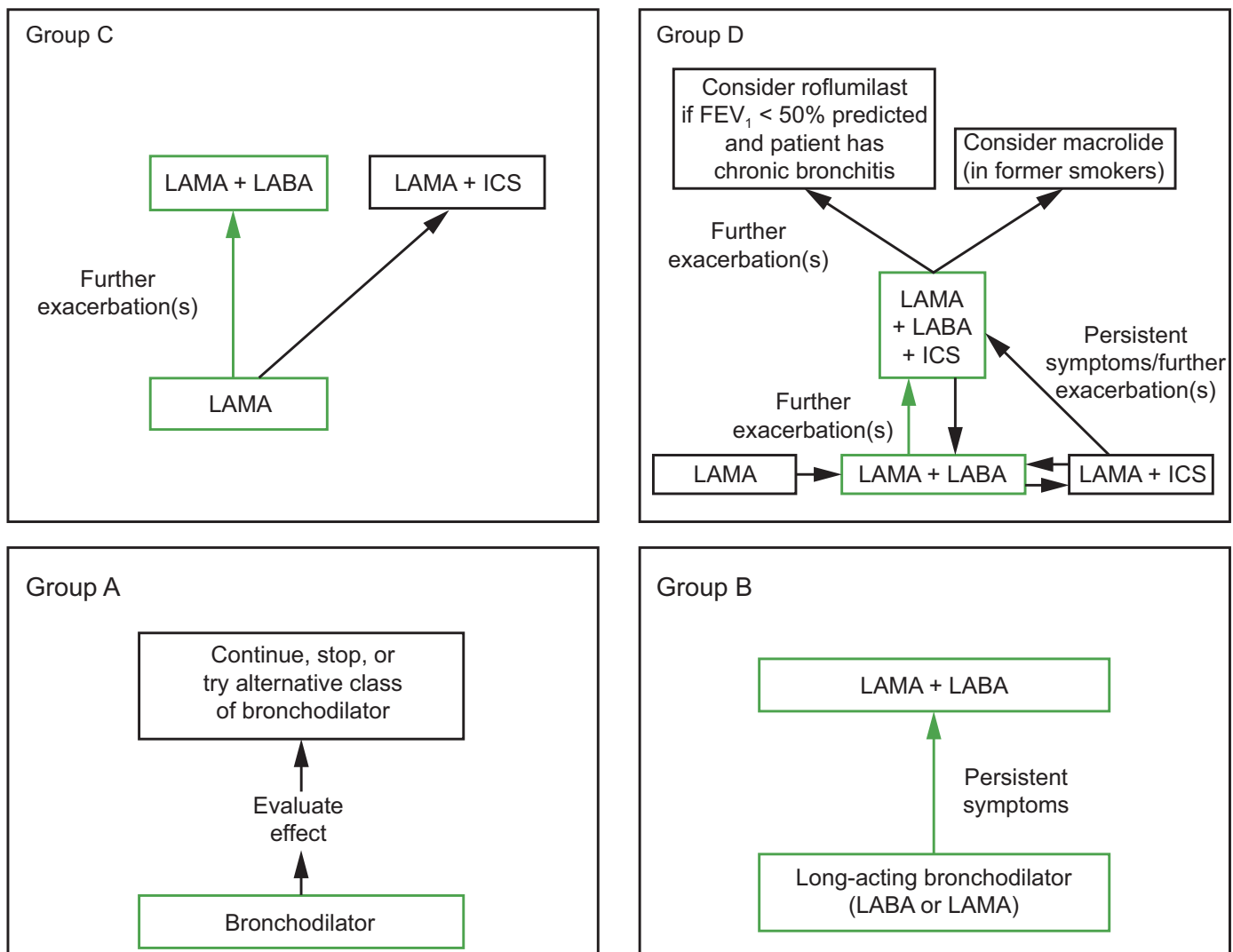

Group B

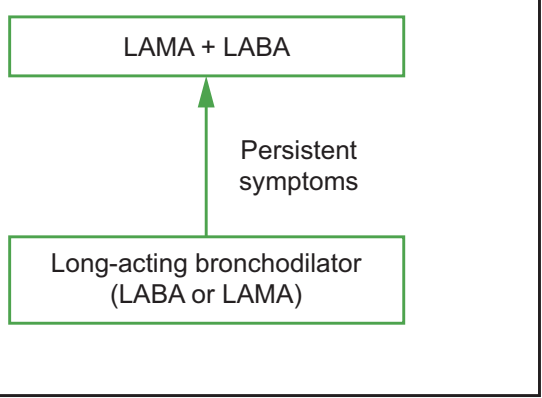

Fig. 2. Choosing inhaler therapy for patients with stable COPD based on the Global Initiative for Chronic Obstructive Lung Disease grouping. Treatments highlighted in green are preferred. LAMA = long-acting muscarinic antagonist; LABA = long-acting $\beta$ agonist; ICS = inhaled corticosteroid. From Reference 1, with permission.

pneumonia, especially in those with a low body mass index, currently smoking, a history of pneumonia, or severe air-flow limitation, and should not be considered the first medication to be added to monotherapy (Fig. 2).1,32

\section{GOLD Group D}

The first-line therapy for GOLD class D is LAMA/LABA, preferably administered in the newer fixed-dose combination inhalers. Combination long-acting bronchodilators are more effective at preventing exacerbation than either of the singular components and decrease exacerbations more than LABA/ ICS combinations. ${ }^{1,18,21}$ Historically, LABA/ICS combinations or "open triple therapy" (a combination of a single LABA/ICS and a single LAMA inhaler) have been used to treat these patients and those with GOLD class $C$ with recurrent exacerbations. ${ }^{8}$ Assessment of the clinical status of the patient is important because a patient with a new diagnosis of COPD and with a history of seeking health care for acute worsening of respiratory issues and current everyday breathlessness may initially benefit from initial initiation of open triple therapy.
Trials of open triple therapy versus monotherapy or dual ICS/LABA show a statistically significant and meaningful improvement in lung function and possible improvement in quality-of-life scores in those on open triple therapy. ${ }^{33}$ Similarly, open triple therapy is superior in reducing exacerbation over monotherapy or dual bronchodilators. ${ }^{5,34}$ As such, the 2017 GOLD guidelines ${ }^{1}$ allow for group D patients to start with a LABA/LAMA and have an ICS added if there are persistent symptoms or further exacerbations, or be started on open triple therapy (as fixed-dose triple therapies remain in development at the time of this writing but have been shown to be non-inferior ${ }^{5}$ to open triple therapies) based on clinical appraisal of the practitioner (Fig. 2).

If the symptoms of a patient in this group are controlled on open triple therapy, then ICS withdrawal can be considered. ${ }^{1}$ In the WISDOM study, ${ }^{35}$ ICS was safely withdrawn via a down-titration over the course of 19 weeks from an open triple inhaler regimen with no increase in time to first exacerbation or rate of exacerbation at the expense of a small $(38 \mathrm{~mL})$ and questionably clinically 
important fall in $\mathrm{FEV}_{1}$. However, and importantly, because peripheral eosinophilia is emerging as a therapeutic target for those with COPD, ${ }^{36}$ patients with $4 \%$ peripheral eosinophils or a total of 400 cells $/ \mu \mathrm{L}$ after withdrawal of ICS had more break-through exacerbations than those with less-marked eosinophilia. ${ }^{37}$ ICS-containing regimens have increased pneumonia risk ${ }^{18}$ compared with LABA/LAMA, and withdrawal of ICS from the regimen of a group D patient should be considered if symptoms are controlled. Further, if the addition of an ICS to LAMA/LABA does not control symptoms, then ICS should be stopped to lessen pneumonia risk. ${ }^{1}$

Patients who remain symptomatic despite therapy should have their inhaler technique assessed and other causes of breathlessness investigated, and should be strongly encouraged to cease any continued smoking. ${ }^{1}$ Oral prophylactic medication can be used for those who have continued exacerbations despite appropriate inhaler therapy. In patients with severe airway obstruction, 2 exacerbations in the year preceding enrollment, and symptoms of chronic bronchitis, the selective, long-acting phosphodiesterase- 4 inhibitor, roflumilast, modestly decreased the rate of exacerbations in patients on LAMA, and, numerically, but not in a statistically significant fashion, in patients on LABA/ICS, with a notable trial dropout rate due to predominantly gastrointestinal symptoms. ${ }^{38,39}$

Macrolide antibiotics decrease the rate and frequency of exacerbations in patients with frequent exacerbations. Macrolides show a more dramatic decrease in patients with $\geq 3$ exacerbations per year and improve quality-of-life scores but are associated with gastrointestinal symptoms and hearing loss when compared with placebo. ${ }^{40-42}$ The American College of Chest Physician guidelines ${ }^{43}$ promote the use of roflumilast or azithromycin for the prevention of COPD exacerbations in appropriately selected patients but caution to mind the possibility of the abovementioned adverse events. Pulsed moxifloxacin $(400 \mathrm{mg} / \mathrm{d}$ every 8 weeks) reduced the odds of exacerbations in those with mucopurulent sputum but was associated with no decrease in rates of hospitalization, mortality, or lung function decline. Pulsed moxifloxacin did not decrease the odds of exacerbation in a general COPD cohort and was associated with an increase in treatment-related adverse events. ${ }^{44}$ Pulsed moxifloxacin utilization is not recommended by the GOLD authors. ${ }^{1}$

Inhaled mucolytics are noted to possibly provide a modest reduction in the exacerbation rate and improvement in quality of life, and are neither promoted nor recommended against by the GOLD guidelines ${ }^{1}$ authors because of uncertainty surrounding ideal patients for this therapy ${ }^{45}$ Methylxanthines (eg, theophylline) have a narrow therapeutic window and unpredictable drug clearance. ${ }^{1}$ Although methylxanthines may provide a small increase in $\mathrm{FEV}_{1}$, the effect on the exacerbation rate is questionable. ${ }^{1,46-48}$ Meth- ylxanthines' adverse effect profile and narrow therapeutic window in light of the uncertain benefit make these unappealing choices in the treatment of the modern patient with COPD. Over the course of treatment, the inhaler technique should be appraised frequently, tobacco cessation counseling should be provided, and pulmonary rehabilitation should be offered to patients on optimal medication regimens for their group with persistent symptoms. ${ }^{1}$

\section{Safety of Inhaled Therapies}

Inhaled medications for COPD are generally considered to be safe. Initial concerns for increased cardiovascular toxicity with LAMAs were not borne out in pooled data of multiple studies. ${ }^{49}$ Likewise, inhaled LABA/ICS do not have adverse cardiovascular effects. ${ }^{50}$ The components of combined LAMA/LABA were not found to be unsafe when compared with monocomponents. ${ }^{51}$ Treatment regimens with an ICS incorporated are associated with an increased risk of pneumonia compared with regimens with bronchodilator therapies alone, and it seems to be inconsequential if an ICS is taken as a monocomponent of an open triple therapy or as part of a single inhaled therapy. ${ }^{18,52,53}$ Fixed triple therapies have not been shown in early studies to have adverse effects other than those known to the individual components. ${ }^{54}$ There may be an increased risk of fracture in patients who take an ICS alone or as part of combined therapy, and fracture and bone mineral density loss risk may differ between the specific ICS and the steroid dose. ${ }^{55-58}$ Inhaled COPD therapies can be considered safe both as monocomponents and in combination, with the largest concern for adverse events being a possible increase in fractures and the well-defined increase risk of pneumonia in those on regimens that contain an ICS.

\section{Summary}

The 2017 GOLD guidelines ${ }^{1}$ offer important changes to the assessment and management of stable COPD. Therapies are now chosen based on patients' history of symptoms and exacerbations, and are modifiable based on clinical reassessment. Although identifying the degree of airway obstruction remains important for informing the clinical status of the patient with COPD, $\mathrm{FEV}_{1}$ is no longer used to direct the therapeutic approach. Although this creates a new diagnostic algorithm for practitioners, the symptoms and exacerbation history occupying their own axis in the classification scheme, (Figure 1) simplify disease classification and therapeutic choices. Therapies for each GOLD grouping have been modified and reflect the need for reassessment of patient symptoms and COPD exacerbation history as impetus to add or withdraw therapies. An efficient and accurate longitudinal symptom assessment encourages a multidisciplinary approach to the patient with 
COPD among practitioners, nurses, pharmacists, and respiratory therapists. As our knowledge of this important disease continues to expand, exacerbation and symptoms prevention in patients with stable COPD will remain an important target of COPD therapies and research. Novel drug combinations and delivery devices are sure to positively affect the practitioners' approach to patients with stable COPD. However, with the multitude of new devices and medications emerging and being incorporated into treatment guidelines, the role of respiratory therapists, pharmacists, and nurses as patient educators will continue to grow as a pivotal part of patient care. The new 2017 GOLD guidelines ${ }^{1}$ represent a step toward personalized care of the patient with COPD.

\section{REFERENCES}

1. Global Initiative for Chronic Obstructive Lung Disease. Global Strategy for the Diagnosis, Management, and Prevention of Chronic Obstructive Pulmonary Disease: 2017 Report. Accessed on December 20, 2017. www.goldcopd.org. Accessed November 2017.

2. Bestall JC, Paul EA, Garrod R, Garnham R, Jones PW, Wedzicha JA. Usefulness of the Medical Research Council (MRC) dyspnoea scale as a measure of disability in patients with chronic obstructive pulmonary disease. Thorax 1999;54(7):581-586.

3. Jones PW, Harding G, Berry P, Wiklund I, Chen WH, Kline Leidy N. Development and first validation of the COPD Assessment Test. Eur Respir J 2009;34(3):648-654.

4. Hurst JR, Vestbo J, Anzueto A, Locantore N, Mullerova H, TalSinger R, et al; Evaluation of COPD Longitudinally to Identify Predictive Surrogate Endpoints (ECLIPSE) Investigators. Susceptibility to exacerbation in chronic obstructive pulmonary disease. New Eng1 J Med 2010;363(12):1128-1138.

5. Vestbo J, Papi A, Corradi M, Blazhko V, Montagna I, Francisco C, et al. Single inhaler extrafine triple therapy versus long-acting muscarinic antagonist therapy for chronic obstructive pulmonary disease (TRINITY): a double-blind, parallel group, randomised controlled trial. Lancet 2017;389(10082):1919-1929.

6. Adi H, Young PM, Traini D. Co-deposition of a triple therapy drug formulation for the treatment of chronic obstructive pulmonary disease using solution-based pressurised metered dose inhalers. J Pharm Pharmacol 2012;64(9):1245-1253.

7. Han MK, Muellerova H, Curran-Everett D, Dransfield MT, Washko GR, Regan EA, et al. GOLD 2011 disease severity classification in COPDGene: a prospective cohort study. Lancet Respir Med 2013; 1(1):43-50.

8. Disease GIfCOL. Global Initiative for Chronic Lung Disease. Global Strategy for the Diagnosis, Management, and Prevention of Chronic Obstructive Pulmonary Disease, Update 2015. www.goldcopd.org 2015. Accessed October 2015.

9. Kim J, Yoon HI, Oh YM, Lim SY, Lee JH, Kim TH, et al. Lung function decline rates according to GOLD group in patients with chronic obstructive pulmonary disease. Int J Chron Obstruct Pulmon Dis 2015;10:1819-1827.

10. Goossens LM, Leimer I, Metzdorf N, Becker K, Rutten-van Molken MP. Does the 2013 GOLD classification improve the ability to predict lung function decline, exacerbations and mortality: a post-hoc analysis of the 4-year UPLIFT trial. BMC Pulm Med 2014;14:163.

11. Nishimura K, Izumi $T$, Tsukino $M$, Oga $T$. Dyspnea is a better predictor of 5-year survival than airway obstruction in patients with COPD. Chest 2002;121(5):1434-1440.
12. Jones PW, Adamek L, Nadeau G, Banik N. Comparisons of health status scores with MRC grades in COPD: implications for the GOLD 2011 classification. Eur Respir J 2013;42(3):647-654.

13. Karloh M, Fleig Mayer A, Maurici R, Pizzichini MMM, Jones PW, Pizzichini E. The COPD Assessment Test: What Do We Know So Far?: A Systematic Review and Meta-Analysis About Clinical Outcomes Prediction and Classification of Patients Into GOLD Stages. Chest 2016;149(2):413-425.

14. Calverley PM, Tetzlaff K, Dusser D, Wise RA, Mueller A, Metzdorf $\mathrm{N}$, Anzueto A. Determinants of exacerbation risk in patients with COPD in the TIOSPIR study. Int J Chron Obstruct Pulmon Dis 2017; 12:3391-3405.

15. Kerstjens HA, Moroni-Zentgraf P, Tashkin DP, Dahl R, Paggiaro P, Vandewalker $M$, et al. Tiotropium improves lung function, exacerbation rate, and asthma control, independent of baseline characteristics including age, degree of airway obstruction, and allergic status. Respir Med 2016;117:198-206.

16. Calverley PM, Anderson JA, Celli B, Ferguson GT, Jenkins C, Jones PW, et al; TORCH Investigators. Salmeterol and fluticasone propionate and survival in chronic obstructive pulmonary disease. N Engl J Med 2007;356(8):775-789.

17. Tashkin DP, Celli B, Senn S, Burkhart D, Kesten S, Menjoge S, Decramer M; UPLIFT Study Investigators. A 4-year trial of tiotropium in chronic obstructive pulmonary disease. N Engl J Med 2008; 359(15):1543-1554.

18. Wedzicha JA, Banerji D, Chapman KR, Vestbo J, Roche N, Ayers $\mathrm{RT}$, et al; FLAME Investigators. Indacaterol-Glycopyrronium versus Salmeterol-Fluticasone for COPD. N Engl J Med 2016;374(23):22222234.

19. Soler-Cataluña JJ, Martínez-García MA, Román Sánchez P, Salcedo E, Navarro M, Ochando R. Severe acute exacerbations and mortality in patients with chronic obstructive pulmonary disease. Thorax 2005; 60(11):925-931.

20. Cazzola M, Rogliani P, Matera MG. Aclidinium bromide/formoterol fumarate fixed-dose combination for the treatment of chronic obstructive pulmonary disease. Expert Opin Pharmacother 2013;14(6): 775-781.

21. Wedzicha JA, Decramer M, Ficker JH, Niewoehner DE, Sandström $\mathrm{T}$, Taylor AF, et al. Analysis of chronic obstructive pulmonary disease exacerbations with the dual bronchodilator QVA149 compared with glycopyrronium and tiotropium (SPARK): a randomised, double-blind, parallel-group study. Lancet Respir Med 2013;1(3):199209.

22. Decramer M, Anzueto A, Kerwin E, Kaelin T, Richard N, Crater G, et al. Efficacy and safety of umeclidinium plus vilanterol versus tiotropium, vilanterol, or umeclidinium monotherapies over 24 weeks in patients with chronic obstructive pulmonary disease: results from two multicentre, blinded, randomised controlled trials. Lancet Respir Med 2014;2(6):472-486.

23. Buhl R, Maltais F, Abrahams R, Bjermer L, Derom E, Ferguson G, et al. Tiotropium and olodaterol fixed-dose combination versus monocomponents in COPD (GOLD 2-4). Eur Respir J 2015;45(4):969979.

24. Kerwin EM, Kalberg CJ, Galkin DV, Zhu CQ, Church A, Riley JH, Fahy WA. Umeclidinium/vilanterol as step-up therapy from tiotropium in patients with moderate COPD: a randomized, parallel-group, 12-week study. Int J Chron Obstruct Pulmon Dis 2017;12:745-755.

25. Farne HA, Cates CJ. Long-acting beta2-agonist in addition to tiotropium versus either tiotropium or long-acting beta2-agonist alone for chronic obstructive pulmonary disease. Cochrane Database Syst Rev 2015(10):CD008989.

26. Ramos M, Haughney J, Henry N, Lindner L, Lamotte M. Cost versus utility of aclidinium bromide $400 \mu \mathrm{g}$ plus formoterol fumarate dihydrate $12 \mu \mathrm{g}$ compared to aclidinium bromide $400 \mu \mathrm{g}$ alone in the 
management of moderate-to-severe COPD. Clinicoecon Outcomes Res 2016;8:445-456.

27. Price D, Keininger D, Costa-Scharplatz M, Mezzi K, Dimova M, Asukai Y, Ställberg B. Cost-effectiveness of the LABA/LAMA dual bronchodilator indacaterol/glycopyrronium in a Swedish healthcare setting. Respir Med 2014;108(12):1786-1793.

28. Hanania NA, Sharafkhaneh A, Celli B, Decramer M, Lystig T, Kesten S, Tashkin D. Acute bronchodilator responsiveness and health outcomes in COPD patients in the UPLIFT trial. Respir Res 2011; 12:6.

29. Calzetta L, Matera MG, Cazzola M. Pharmacological interaction between LABAs and LAMAs in the airways: optimizing synergy. Eur J Pharmacol 2015;761:168-173.

30. Vogelmeier C, Hederer B, Glaab T, Schmidt H, Rutten-van Mölken MP, Beeh KM, et al. Tiotropium versus salmeterol for the prevention of exacerbations of COPD. N Engl J Med 2011;364(12):1093-1103.

31. Decramer ML, Chapman KR, Dahl R, Frith P, Devouassoux G, Fritscher $\mathrm{C}$, et al; INVIGORATE investigators. Once-daily indacaterol versus tiotropium for patients with severe chronic obstructive pulmonary disease (INVIGORATE): a randomised, blinded, parallel-group study. Lancet Respir Med 2013;1(7):524-533.

32. Crim C, Dransfield MT, Bourbeau J, Jones PW, Hanania NA, Mahler DA, et al. Pneumonia risk with inhaled fluticasone furoate and vilanterol compared with vilanterol alone in patients with COPD. Ann Am Thorac Soc 2015;12(1):27-34.

33. Siler TM, Kerwin E, Sousa AR, Donald A, Ali R, Church A. Efficacy and safety of umeclidinium added to fluticasone furoate/vilanterol in chronic obstructive pulmonary disease: Results of two randomized studies. Respir Med 2015;109(9):1155-1163.

34. Sousa AR, Riley JH, Church A, Zhu CQ, Punekar YS, Fahy WA. The effect of umeclidinium added to inhaled corticosteroid/longacting beta2-agonist in patients with symptomatic COPD: a randomised, double-blind, parallel-group study. NPJ Prim Care Respir Med 2016;26:16031.

35. Magnussen H, Disse B, Rodriguez-Roisin R, Kirsten A, Watz H, Tetzlaff $\mathrm{K}$, et al; WISDOM Investigators. Withdrawal of inhaled glucocorticoids and exacerbations of COPD. N Engl J Med 2014; 371(14):1285-1294.

36. Pavord ID, Chanez P, Criner GJ, Kerstjens HAM, Korn S, Lugogo N, et al. Mepolizumab for Eosinophilic Chronic Obstructive Pulmonary Disease. N Engl J Med 2017;377(17):1613-1629.

37. Watz H, Tetzlaff K, Wouters EF, Kirsten A, Magnussen H, Rodriguez-Roisin R, et al. Blood eosinophil count and exacerbations in severe chronic obstructive pulmonary disease after withdrawal of inhaled corticosteroids: a post-hoc analysis of the WISDOM trial. Lancet Respir Med 2016;4(5):390-398.

38. Martinez FJ, Calverley PM, Goehring UM, Brose M, Fabbri LM, Rabe KF. Effect of roflumilast on exacerbations in patients with severe chronic obstructive pulmonary disease uncontrolled by combination therapy (REACT): a multicentre randomised controlled trial. Lancet 2015;385(9971):857-866.

39. Martinez FJ, Rabe KF, Sethi S, Pizzichini E, McIvor A, Anzueto A, et al. Effect of Roflumilast and Inhaled Corticosteroid/Long-Acting $\beta 2$-Agonist on Chronic Obstructive Pulmonary Disease Exacerbations (RE(2)SPOND). A Randomized Clinical Trial. Am J Respir Crit Care Med 2016;194(5):559-567.

40. Seemungal TA, Wilkinson TM, Hurst JR, Perera WR, Sapsford RJ, Wedzicha JA. Long-term erythromycin therapy is associated with decreased chronic obstructive pulmonary disease exacerbations. Am J Respir Crit Care Med 2008;178(11):1139-1147.

41. Uzun S, Djamin RS, Kluytmans JA, Mulder PG, van't Veer NE, Ermens AA, et al. Azithromycin maintenance treatment in patients with frequent exacerbations of chronic obstructive pulmonary dis- ease (COLUMBUS): a randomised, double-blind, placebo-controlled trial. Lancet Respir Med 2014;2(5):361-368.

42. Albert RK, Connett J, Bailey WC, Casaburi R, Cooper JA Jr, Criner GJ, et al; COPD Clinical Research Network. Azithromycin for prevention of exacerbations of COPD. N Engl J Med 2011;365(8):689-698.

43. Criner GJ, Bourbeau J, Diekemper RL, Ouellette DR, Goodridge D, Hernandez P, et al. Prevention of acute exacerbations of COPD: American College of Chest Physicians and Canadian Thoracic Society Guideline. Chest 2015;147(4):894-942.

44. Sethi S, Jones PW, Theron MS, Miravitlles M, Rubinstein E, Wedzicha JA, Wilson R; PULSE Study group. Pulsed moxifloxacin for the prevention of exacerbations of chronic obstructive pulmonary disease: a randomized controlled trial. Respir Res 2010;11:10.

45. Poole P, Chong J, Cates CJ. Mucolytic agents versus placebo for chronic bronchitis or chronic obstructive pulmonary disease. Cochrane Database Syst Rev 2015(7):CD001287.

46. Cosío BG, Shafiek H, Iglesias A, Yanez A, Córdov R, Palou A, et al. Oral Low-dose Theophylline on Top of Inhaled Fluticasone-Salmeterol Does Not Reduce Exacerbations in Patients With Severe COPD: A Pilot Clinical Trial. Chest 2016;150(1):123-130.

47. Zacarias EC, Castro AA, Cendon S. Effect of theophylline associated with short-acting or long-acting inhaled beta2-agonists in patients with stable chronic obstructive pulmonary disease: a systematic review. J Bras Pneumol 2007;33(2):152-160.

48. Ram FS, Jones PW, Castro AA, De Brito JA, Atallah AN, Lacasse $\mathrm{Y}$, et al. Oral theophylline for chronic obstructive pulmonary disease. Cochrane Database Syst Rev 2002(4):CD003902.

49. Tashkin DP. Long-acting anticholinergic use in chronic obstructive pulmonary disease: efficacy and safety. Curr Opin Pulm Med 2010; 16(2):97-105.

50. Brook RD, Anderson JA, Calverley PM, Celli BR, Crim C, Denvir MA, et al; SUMMIT Investigators. Cardiovascular outcomes with an inhaled beta2-agonist/corticosteroid in patients with COPD at high cardiovascular risk. Heart 2017;103(19):1536-1542.

51. Frampton JE. QVA149 (indacaterol/glycopyrronium fixed-dose combination): a review of its use in patients with chronic obstructive pulmonary disease. Drugs 2014;74(4):465-488.

52. Cavallazzi R, Singh S. Inhaled Corticosteroids in Chronic Obstructive Pulmonary Disease: How Significant is the Risk of Pneumonia and Should It Impact Use of Inhaled Corticosteroids? Curr Infect Dis Rep 2011;13(3):296-301.

53. Calverley PMA, Magnussen H, Miravitlles M, Wedzicha JA. Triple Therapy in COPD: What We Know and What We Don't. COPD 2017;14(6):648-662.

54. Lipson DA, Barnacle H, Birk R, Brealey N, Locantore N, Lomas DA, et al. FULFIL Trial: Once-Daily Triple Therapy for Patients with Chronic Obstructive Pulmonary Disease. Am J Respir Crit Care Med 2017;196(4):438-446.

55. Loke YK, Cavallazzi R, Singh S. Risk of fractures with inhaled corticosteroids in COPD: systematic review and meta-analysis of randomised controlled trials and observational studies. Thorax 2011; 66(8):699-708.

56. Tsai CH, Liao LY, Lin CL, Chung WS. Inhaled corticosteroids and the risks of low-energy fractures in patients with chronic airway diseases: A propensity score matched study. Clin Respir J 2017 [Epub ahead of print] doi: 10.1111/crj.12744

57. Cho KH, Kim YS, Linton JA, Nam CM, Choi Y, Park EC. Effects of inhaled corticosteroids /long-acting agonists in a single inhaler versus inhaled corticosteroids alone on all-cause mortality, pneumonia, and fracture in chronic obstructive pulmonary disease: A nationwide cohort study 2002-2013. Respir Med 2017;130:75-84.

58. Putcha N, Drummond MB. Inhaled corticosteroids for people with chronic obstructive pulmonary disease are associated with an increased risk of fracture. Evid Based Med 2012;17(3):90-91. 


\section{Discussion}

Wechsler: It seems to me that you like to start off triple and then you say you step back, so what is your preferred stepping back to?

Donohue: Most of the time I am starting with LAMA/LABA in COPD so it would be stepping back down from a triple. There are differences I've found in my studies and in our meta-analyses between LABAs and LAMAs. The LAMAs are better on exacerbations than the LABAs, everything else is a wash if you use an effective LABA. The role of the fixed-dose triple though is the big question, and we have a really good track record of ICS/LABAs in the United States for COPD, and we know that LABA/LAMAs are very effective on lung function and patient-reported outcomes. The study by Magnussen et $\mathrm{al}^{1}$ was of stepping down from a triple to an LABA/LAMA.

Wechsler: LABA/LAMA versus what?

Donohue: Triple. ICS/LABA/LAMA.

Wechsler: OK. But, are there data for stepping down to LAMA/LABA versus LABA/ICS?

Donohue: No. There is just guidance on that if you take from the Watz et $\mathrm{al}^{2}$ subset analysis of the Wisdom study if you have $4 \%$ eosinophils or a total of 300 cells, that's really dangerous to withdraw ICS, you're going to get exacerbation breakthrough. So if you have asthma, COPD overlap, or elevated eosinophils, or, in my view, if you have severe disease or frequent exacerbations, don't take that steroid away. The data do not support, as I just showed in the FLAME study, ${ }^{3}$ taking an ICS away when a patient's disease is real severe.

Wise: I can't wait to read your paper, that was a great talk and I think you are correct. I agree with your view on the FLAME study. ${ }^{3}$ Many people are interpreting that as a class effect of LABA/LAMA versus ICS/LABA. The study compared a once-a-day drug with a dose that's higher than is available in the United States against a twicea-day drug that does not have the same bronchodilation of indacaterol. ${ }^{4}$ So, it is certainly a fair comparison of one specific drug against another but not a comparison of the class of LABA/LAMA versus ICS/LABA.

Donohue: I think you're right, but there is little evidence to support that. Only Novartis studies really consistently find this, Novartis had another one and I think the jury is out on that. What bothers me is that when GlaxoSmithKline does the study you get one result, and Novartis does a study and gets another result. How does that happen?

Wise: I think the answer is going to be in these triple studies, GlaxoSmithKline's IMPACT, 5 and the Pearl $^{6}$ and Chiesi ${ }^{7}$ studies in which you'll be able to compare the triple with each of the 2 doubles. These will provide a clearer comparison of LABA/LAMA versus ICS/LABA.

Donohue: Yes, and the FDA will put the appropriate comparison in which I think is excellent.

Wise: Yes. So there I think we'll have some very probative evidence soon coming out. I don't think the FLAME study ${ }^{3}$ really settled that issue in my view.

*Hess: I think you very quickly showed a picture of an eFlow device (Pari, Starnberg, Germany) and said there was a glycopyrrolate formulation being developed for that. For our RT readers, I want to make the point that many of these new formulations are designed for a specific nebulizer. This is an example of that, and there are other examples we could cite.
Donohue: Right. To back that up, the company (Sunovion Pharmaceuticals, Marlborough, MA) will provide the eFlow to each patient who is starting nebulized glycopyrrolate. Sunovion is going to be comparing themselves to a traditional jet nebulizer with Theravance's (Therovance Biopharma, San Francisco, CA) 24-h LAMA refenacin, and Sunovion are apparently going to give the eFlow away.

*Hess: You are getting right to the point that I wanted to make. What happens in many hospitals, I have seen it with TOBI (inhalable tobramycin); for example, is that, even though the drug is cleared for a specific nebulizer, what RTs will do is choose the cheapest nebulizer on the market and dump that drug into that device. But that is not how the drug was studied, FDAcleared, or marketed.

Donohue: This is going to be increasingly important because as we mentioned earlier, the nebulizer is the only way to deliver these other types of drugs. I've been involved with the liposomal amikacin for Mycobacterium and aerosol antibiotics in bronchiectasis. ${ }^{8,9}$ There's a variety of new inhalers, to be used with new delivery devices. We'll be challenged with all these new inhaled drugs and antibiotics.

Mann: Just a comment. If I could tell you the most common questions that I get as a regulatory consultant 13 years out of the FDA are "how does the FDA pick the right dose of a bronchodilator? What are they looking for?" I get those questions all the time and I heard you in your talk say that the FDA thinks that glycopyrrolates are a twice-a-day drug.

Donohue: With good reason.

Mann: With good reason, yes. But I want to be very clear that the FDA looks at every drug as unique, its device is unique, the formulation is unique. It may be that one person could 
potentially develop a glycopyrrolate salt that's longer acting or a glycopyrrolate delivery system device that prolongs the duration of action to once a day. So I don't think the FDA characterize a given moiety as twice a day forever and ever, they allow companies to prove it with data and try to substantiate with data whether it's a once-a-day drug, a twice-a-day drug, or even a 3-times-a-day drug. The regulatory approach is to look at the full $\mathrm{FEV}_{1}$ curves over the dosing interval to try to assure the optimal dose as well as the regimen. There are no magic trough numbers. A trough of $\sim 80 \mathrm{~mL}$ is about the lowest I've seen for a long-acting bronchodilator, so, given that precedence, shooting for close to 100 is reasonable. Sometimes, to gain a once-daily administration, a larger dose can be administered, but if that larger dose offers more adverse effects as well, then a lower dose twice a day or even 3-times-a-day approach may be suggested. There's no magical formula for it, but if you think your drug works once a day, the agency may ask you to compare once-a-day to twice-a-day dosing regimens at the same nominal dose.

Donohue: One thing the FDA made me do with indacaterol was really prove that you're not able to reduce the total drug exposure by giving it twice a day or every other day. I thought that was kind of cool. The other thing is you see all of these longacting drugs and on the dose-response they're relatively flat. Marianne [Mann] makes a good point, if you look at a peak level (and this is what happened with Foradil 24 (Novartis International, Basel, Switzerland) in asthma, the higher value led to asthma hospitalizations in those big asthma trials). ${ }^{10,11,12}$ You want to look at your peak:trough, and if it's really large, then be careful because the FDA may be concerned.

Mann: A very good example of a high peak:trough is arformoterol
(Sunovion), at least for the once-a-day dosing. Arformoterol needed a dose increase to get a sustained once-a-day trough effect and it didn't work out for Sunovion. So, when looking at that application, you can see that the $\mathrm{FEV}_{1}$ curves had a high peak-to-trough ratio to gain a reasonable trough $\mathrm{FEV}_{1}$ effect, and, in the clinical database, you saw that people exposed to the oncea-day regimen had more tremor as well. Lower doses of arformoterol administered twice a day worked much better with less toxicity. It really did substantiate that you need to do the job right in having the dose and dosing frequency be very fully substantiated. The goal is always to get the lowest systemic exposure but with the most optimal $\mathrm{FEV}_{1}$ benefit, and, of course, those 2 objectives sort of compete with one another. But, if you can keep the exposure low and get fairly good bronchodilatory benefit, the FDA is happy and that's the goal, getting the drug labeled and cleared.

Wechsler: Two questions, one relates to as-needed use of quick onset short-acting ICS/LABA as is used with the combination of formoterol and budesonide in asthma. Have there been studies that used ICS/LABA as an asneeded long acting? My second question related to the use of biomarkers and endotyping in COPD in which it seems that COPD is eons behind asthma. Not that asthma is that far advanced, frankly. Where do we stand other than we are just starting to use blood and/or sputum eosinophils, but what about other biomarkers? And why is there so little there?

MacIntyre: I would hold off on the first one until Njira [Lugogo] gives her presentation on asthma, if we could. Bring it up again then, Mike. Let's focus on COPD if we could.

Wechsler: I will. The second question then, about biomarkers.
Donohue: The biomarkers consortium that the late John Walsh convened with the FDA and National Institutes of Health and industry. ${ }^{13}$ That was published. I remember it because the editor of the journal $C O P D$ said that, because you are the only guy in the country who was not invited to participate, will you be the reviewer and write the editorial?13 I said, "Gee, I'm honored." So those are just a part of it, and maybe Neil [MacIntyre] could chime in because a lot of that is part of SPIROMICS and phenotypes. Those are fibrinogen, things like the 6MWT, that biomarker is being looked at and the St George's Respiratory Questionnaire ${ }^{14}$ I guess. Jerry Turino's urinary desmosine for emphysema. So, those are beginnings, but it's in its infancy.

Mann: I think the fibrinogen is the only one that gained FDA clearance. ${ }^{10}$ All the others are listed under the consortium as being looked at, but the fibrinogen in 2015 was the first time that the FDA cleared a biomarker for early studies in COPD. ${ }^{15}$ So we are making progress.

Wise: I think the term biomarkers in that sense is different than how Mike [Wechsler] is using it. The FDA qualification process is clearing them as intermediate outcome measures rather than ways of evaluating endotypes or heterogeneity of treatment effects.

Wechsler: Part of the reason we're using biomarkers is that we're recognizing the heterogeneity of the disease but also because we now have drugs that target those specific pathways and that may not be the case in COPD. Although, maybe mepolizumab or one of the other anti-interleukin-5s, such as benralizumab, may be effective.

\section{REFERENCES}

1. Magnussen H, Disse B, Rodriguez-Roisin $\mathrm{R}$, Kirsten A, Watz $\mathrm{H}$, Tetzlaff $\mathrm{K}$, et al; WISDOM Investigators. Withdrawal of in- 


\section{Update on GOLD: Classification and Management}

haled glucocorticoids and exacerbations of COPD. N Engl J Med 2014;371(14):12851294.

2. Watz H, Tetzlaff $\mathrm{K}$, Wouters EF, Kirsten A, Magnussen $\mathrm{H}$, Rodriguez-Roisin $\mathrm{R}$, et al. Blood eosinophil count and exacerbations in severe chronic obstructive pulmonary disease after withdrawal of inhaled corticosteroids: a post-hoc analysis of the WISDOM trial. Lancet Respir Med 2016; 4(5):390-398

3. Wedzicha JA, Banerji D, Chapman KR, Vestbo J, Roche N, Ayers RT, et al.; FLAME Investigators. IndacaterolGlycopyrronium versus Salmeterol-Fluticasone for COPD. N Engl J Med 2016; 374(23):2222-2234.

4. Wedzicha JA, Buhl R, Lawrence D, Young D. Monotherapy with indacaterol once daily reduces the rate of exacerbations in patients with moderate-to-severe COPD: Post-hoc pooled analysis of 6 months data from three large phase III trials. Respir Med 2015; 109(1):105-111.

5. Lipson DA, Barnhart F, Brealey N, Brooks J, Criner GJ, Day NC, et al; IMPACT investigators. Once-daily single-inhaler triple versus dual therapy in patients with COPD. N Engl J Med 2018;378(18):16711680.

6. Darken P, DePetrillo P, Reisner C, St Rose E, Dorinsky P. The pharmacokinetics of three doses of budesonide/glycopyrronium/ formoterol fumarate dihydrate metered dose inhaler compared with active controls: A Phase I randomized, single-dose, crossover study in healthy adults. Pulm Pharmacol Ther 50(2018):11-18.

7. Singh D, Papi A, Corradi M, Pavlišová I, Montagna I, Francisco C, Cohuet G, Vezzoli S, Scuri M, Vestbo J. Single inhaler triple therapy versus inhaled corticosteroid plus long-acting $\beta 2$-agonist therapy for chronic obstructive pulmonary disease (TRILOGY): a double-blind, parallel group, randomised controlled trial. Lancet 2016; 388(10048):963-973.

8. Olivier KN, Shaw PA, Glaser TS, Bhattacharyya D, Fleshner M, Brewer CC, Zalewski CK, Folio LR, Siegelman JR, Shallom S, Park IK. Inhaled amikacin for treatment of refractory pulmonary nontuberculous mycobacterial disease. Ann Am Thorac Soc 2014;11(1):30-35.

9. Henkle E, Aksamit TR, Barker AF, Curtis JR, Daley CL, Anne Daniels ML, et al. Pharmacotherapy for Non-Cystic Fibrosis Bronchiectasis: Results From an NTM Info \& Research Patient Survey and the Bronchiectasis and NTM Research Registry. Chest 2017;152(6):1120-1127.

10. Trifilieff A, editor. Indacaterol: The First Once-daily Long-acting Beta2 Agonist for COPD. Springer Science \& Business Media; 2013 Nov 19.
11. Mann M, Chowdhury B, Sullivan E, Nicklas R, Anthracite R, Meyer RJ. Serious asthma exacerbations in asthmatics treated with high-dose formoterol. Chest 2003; 124(1):70-74.

12. Cates CJ, Wieland LS, Oleszczuk M, Kew KM. Safety of regular formoterol or salmeterol in adults with asthma: an overview of Cochrane reviews. Cochrane Database Syst Rev 2014;(2):CD010314.

13. Casaburi R, Celli B, Crapo J, Criner G, Croxton T, Gaw A, Jones P, Kline-Leidy N, Lomas DA, Merrill D, Polkey M. The COPD biomarker qualification consortium (CBQC). J COPD 2013 Jun 1;10(3):367377.

14. Jones PW, Quirk FH, Baveystock CM, Littlejohns P. A self-complete measure of health status for chronic airflow limitation. The St. George's Respiratory Questionnaire. Am Rev Respir Dis 1992;145:13211327.

15. Turino GM, Lin YY, He J, Cantor JO, Ma S. Elastin degradation: an effective biomarker in COPD. COPD 2012;9(4):435438.

* Dean R Hess PhD RRT FAARC, discussant. Dr Hess is Managing Editor of ResPIRATORY CARE. 